\title{
Mn-Catalyzed Oxidation of Multiple-Ringed Aromatics
}

\author{
GENE WHELAN and RONALD C. SIMS \\ Division of Environmental Engineering \\ Civil and Environmental Engineering Department \\ Utah State University \\ Logan, UT 84322-4110
}

\begin{abstract}
The role of manganese (Mn) oxides in catalyzing the abiotic oxidation of polynuclear aromatic compounds (PNAs) has been investigated by monitoring the oxidation of dihydrodiol and dione PNAs and corresponding reduction of $\mathrm{Mn}$ in an aqueous environment. 1,4-, 1,3-, and 2,3naphthalenediol, 1,4-naphthoquinone, and 1,4-dihydroxy-9,10-anthracenedione (Quinizarin) were oxidized in an oxic, aqueous environment, where each of these organic compounds is soluble in water, except Quinizarin. A mathematical model is presented, which describes the redox reactions, and suggests that electron transfer/organic release from the oxide surface is rate limiting with the reaction apparently proceeding through a free-radical formation. Results indicate significant oxidation of the organics, that the oxidation of the diols is kinetically more favorable than that of the dione, and that lower molecular weight PNAs containing diol and dione functional groups are susceptible to abiotic-catalyzed oxidation, thereby suggesting that progressively more complex PNA molecules may also be susceptible to oxidation.
\end{abstract}

\section{INTRODUCTION}

Research addressing pesticides and single-ringed phenolic compounds has identified important environmental fate mechanisms, including enzymatic- and abiotic-catalyzed oxidation that often results in polymerization of pesticide molecules [1-4]. Qiu and McFarland [5] studied degradation/transformation of $\left[{ }^{14} \mathrm{C}\right]$ benzo(a)pyrene $[\mathrm{B}(\mathrm{a}) \mathrm{P}]$ in two different soils with and without Phanerochaete chrysosporium inoculation. They noted that mass balance considerations suggested that the enhanced removal of $\mathrm{B}(\mathrm{a}) \mathrm{P}$ resulted in the formation of immobilized bound residues in soil, and humification rather than conversion to $\mathrm{CO}_{2}$ was the major reaction observed.

Abiotic-catalyzed oxidation and polymerization of polynuclear aromatic compounds (PNAs) generally have not been evaluated with regard to occurrence, behavior, or treatment approaches within soil and groundwater environments, although smaller phenolic compounds have been investigated. Shindo and Huang [6,7] showed that birnessite is powerful in promoting the abiotic degradation of diphenols leading to the subsequent formation of humic polymers. McBride [8] studied the $\mathrm{O}_{2}$ consumption rate during the oxidation of polyphenols by manganese $(\mathrm{Mn})$ oxides. Mn oxides play a direct role in oxidation, possibly because oxide surfaces chemisorb many phenols and other aromatic acids [9]. 
Schnitzer [2] suggested that the rate-determining step in the oxidative polymerization of humic acids from simple phenols and phenolic acids is the formation of a semiquinone radical involving a one-electron transfer reaction. These relatively unstable and reactive semiquinone radicals will couple with each other to form a stable humic acid polymer. Shindo and Huang [10] suggested that the Mn oxide accelerated the darkening of hydroquinone via electron transfer. In previous work, Kononova [11] and Schnitzer and Kahn [12] made statements similar to that of Shindo and Huang [6] regarding the polymerization of hydroquinone through a semiquinone radical $[13,14]$. Laha and Luthy [15] also noted polymerized products while investigating oxidation of aniline with $\delta-\mathrm{MnO}_{2}$ under sterile, anoxic conditions at low $\mathrm{pH}$.

McBride et al. [4] proposed a low-pH mechanism for the role of aluminum (Al) in promoting oxidative polymerization of phenolic compounds. Lehmann and Cheng [16] demonstrated the oxidation of phenolic acids in the presence of $\mathrm{MnO}_{2}$ to form products with higher molecular weights than their parent compounds. In a previous study, Lehmann et al. [17] reported that phenolic acids abiotically reacted with soil $\mathrm{Mn}$ oxides in a redox reaction where the Mn was reduced to $\mathrm{Mn}(\mathrm{II})$ and the phenolic acids oxidized.

Manganese-bearing particles have demonstrated a catalytic effect in enhancing the oxidation of multiple-ringed aromatics. Mihelcic and Luthy [18] investigated the oxidation of $\alpha$ naphthol using reductive dissolution of $\mathrm{Mn}$ dioxide particles under denitrification conditions. They reported complete degradation of the naphthol after 12 days.

The purpose of this research was to investigate the nature of redox reactions in a simplified aqueous system consisting of various PNA derivatives and $\mathrm{MnO}_{2}$ and to present a possible mathematical explanation of this abiotic process. Because of its redox potential, Mn oxides were used to oxidize the following five multiple-ringed aromatic compounds containing diol and dione functional groups under oxic conditions: 1,4-, 1,3-, and 2,3-naphthalenediol $\left[\mathrm{C}_{10} \mathrm{H}_{6}(\mathrm{OH})_{2}\right], 1,4-$ naphthoquinone $\left(\mathrm{C}_{10} \mathrm{H}_{6} \mathrm{O}_{2}\right)$, and 1,4-dihydroxy-9,10-anthracenedione [Quinizarin, $\mathrm{C}_{14} \mathrm{H}_{6} \mathrm{O}_{2}(\mathrm{OH})_{2}$ ] (see Figure 1). Stoichiometric relationships between a PNA substrate and $\mathrm{Mn}$ particles are reviewed. Naphthalenediol has been used to illustrate these relationships; any one of the other PNAs could also have been chosen, resulting in a similar outcome. Manganese reductive dissolution and PNA oxidation were mathematically approached from experimental and theoretical perspectives. An initial set of mathematical expressions was developed based on experimental data; these expressions were then compared to theoretically derived equations based on stoichiometric and kinetic considerations.

\section{MATERIALS AND METHODS}

All solutions were prepared from reagent grade chemicals and deionized distilled water (DDW) and filtered with a $0.2-\mu \mathrm{m}$-pore-diameter, nylon membrane filter (Nylaflo, Baxter Scientific Products) prior to use. All glassware was soaked in $2 \mathrm{~N} \mathrm{HNO}_{3}$ and $0.05 \mathrm{M}$ $\mathrm{NH}_{2} \mathrm{OH} \cdot \mathrm{HCl}$, and thoroughly rinsed with DDW prior to use. The following reagent grade chemicals were used in these experiments: 1,4-naphthalenediol (Fluka 97\%), 2,3-naphthalenediol (Aldrich 98\%), 1,3-naphthalenediol (Fluka 99\%), 1,4-naphthoquinone (Fluka 99\%), and Quinizarin (Alfa 98\%).

A series of triplicate 50-mL KIMAX centrifuge tubes with Teflon-lined septum (Thomas Scientific, 2390-H72) and screw caps were prepared under oxic conditions for each sample and control; no attempt was made to establish an anoxic environment. Sample tubes contained 3 $\times 10^{-4} \mathrm{M} \mathrm{MnO}_{2}, 4 \times 10^{-4} \mathrm{M}$ organic substrate, $1.00 \times 10^{-3} \mathrm{M}$ acetate-buffer $\left(6.95 \times 10^{-4} \mathrm{M}\right.$ sodium acetate and $3.48 \times 10^{-4} \mathrm{M}$ acetic acid) solution (initial $\mathrm{pH}$ of buffer measured as 4.58), and 1.0 $x 10^{-3} \mathrm{M} \mathrm{NaClO}_{4}$ (to help fix ionic strength) in a $0.2-\mu \mathrm{m}$-filtered DDW solution. Manganese dioxide particles were prepared using a procedure based on Murray [19] and Godtfredsen [20] and described by Whelan [21] and Whelan and Sims [22]. Triplicate controls were prepared for $\mathrm{Mn}$ dioxide and organic substrate, in which triplicate tubes identical to the samples were prepared without $\mathrm{MnO}_{2}$ particles and organic substrate, respectively. All tubes were prepared under yellow light and stored in the dark to minimize photodegradation. Prior to analysis, the tubes were stored in the dark under the same environmental conditions and tumbled at 30 rpms. 


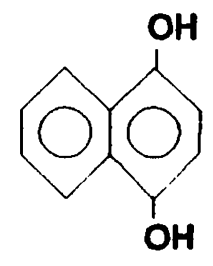

1.4-Naphthalenedlol

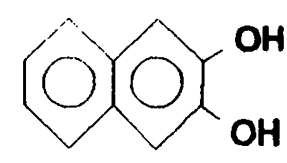

23-Naphthalenediol

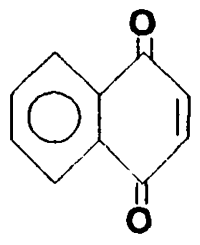

1.4Naphthoquinone

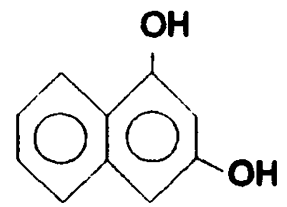

1,3-Naphthalenediol

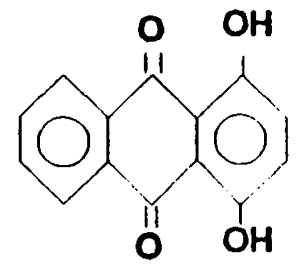

1,4-Dinydroxy-9,10-anthracenedione

(Quinizarin)

FIGURE 1. Schematic Diagram of 1,4-, 2,3-, 1,3-Naphthalenediol, 1,4-Naphthoquinone, and 1,4-Dihydroxy-9,10-Anthracenedione.

Because the experimental centrifuge tubes essentially contained only Mn and organic substrate, the experimental design focused on monitoring $\mathrm{Mn}$ and the parent organic substrate. Dissolved $\mathrm{Mn}^{2+}$ and the parent organic substrate were monitored with Inductively Coupled Plasma (ICP, Perkin-Elmer ICP/6000) and High Performance Liquid Chromatography (HPLC), respectively. A description of the instruments and their respective settings are described by Whelan [21].

Once the sample and control tubes were prepared and tumbled, they were sacrificed (i.e., no subsampling) at days $0,1,4,7$, and 14. The tubes were centrifuged (Beckman J2-21) at 3000 rpms for 10 minutes. The supernatant was filtered through a $0.2-\mu \mathrm{m}$ nylon filter using a Millipore filtering apparatus. Twenty milliliters of the filtrate were dropwise acidified to a $\mathrm{pH}$ of 3 using $1 \mathrm{~N} \mathrm{NH} \mathrm{NH}_{2} \mathrm{OH} \cdot \mathrm{HCl}$ and $0.1 \mathrm{~N} \mathrm{HNO}_{3}$, after acidification the filtrate was diluted to $50 \mathrm{~mL}$ using an acetate-buffered/ $/ \mathrm{NaClO}_{4}-\mathrm{DDW}$ solution with a $\mathrm{pH}$ of 3 . The residual-centrifuged solids and solids retained on the nylon filter were acidified to a $\mathrm{pH}$ of 3 , combined, and diluted to $50 \mathrm{~mL}$ using an acetate-buffered $/ \mathrm{NaClO}_{4}$-DDW solution with a pH of 3 . Each final solution contained $1.0 \times 10^{-3} \mathrm{M} \mathrm{NaClO}_{4}$ and a pH of 3 . All standards were prepared under the same conditions as samples and controls and at a $\mathrm{pH}$ and ionic strength consistent with samples and controls.

\section{RESULTS}

This study examined the effectiveness of employing Mn oxide particles to oxidize certain multiple-ringed aromatic compounds. The effectiveness is illustrated in Figures 2 and 3 and Table 1. Figure 2 presents time variations in the $\mathrm{Mn}^{2+}$ concentration by constituent, expressed as a fraction of the total Mn added to the reaction vessel. Separate Mn control tubes were prepared for each constituent for each time period, and no significant $\mathrm{Mn}^{2+}$ appeared in the controls. Because both forms of $\mathrm{Mn}$ (i.e., dissolved and particles) were monitored, a mass balance could be performed. Table 1a presents the percentage of total $\mathrm{Mn}$ as $\mathrm{Mn}^{2+}$ with $95 \%$ confidence limits for each of the five PNA compounds.

To indicate the degree of oxidation of the parent organics by Mn particles, Figure 3 presents the fraction of the organic oxidized (i.e., molar ratio of organic oxidized to organic con- 


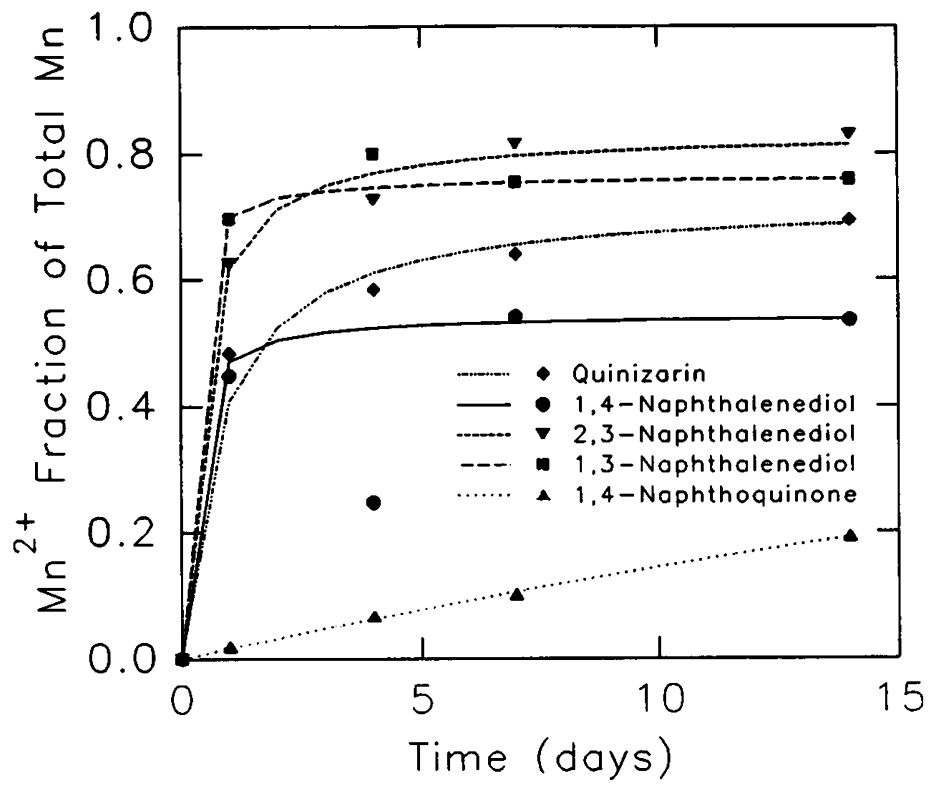

FIGURE 2. Time-Varying Fraction of the Total Manganese as Dissolved $\mathbf{M n}^{2}$ for an Initial Concentration and $\mathrm{pH}$ of $4 \times 10^{-4} \mathrm{M}$ and 4.58 , respectively.

trol). For example, a 0.99 value in this figure indicates that $99 \%$ of the parent organic has been oxidized (either transformed or degraded). The possibility of sorption by the parent organic has been accounted for by dissolving the $\mathrm{Mn}$ particles at a $\mathrm{pH}$ of 3 and monitoring any released parent. The time varying mass associated with the controls and sample vessels is presented in Table $1 b$.

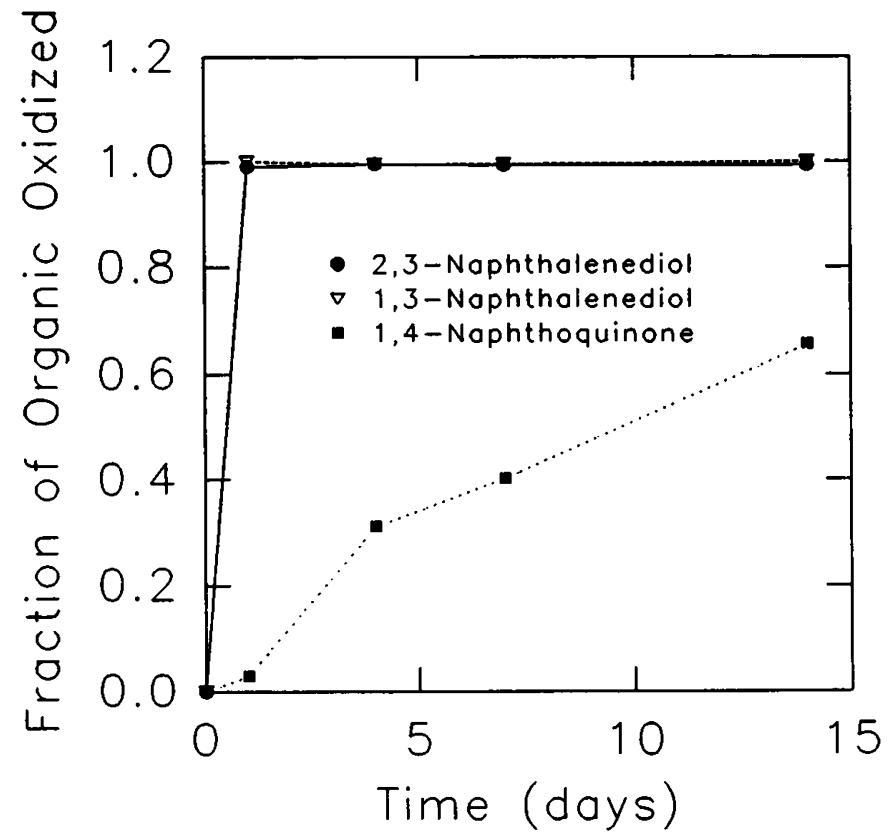

FIGURE 3. Fraction of the Organic Substrate Oxidized During Reductive Dissolution for an Initial Concentration and $\mathrm{pH}$ of $4 \times 10^{-4} \mathrm{M}$ and 4.58, respectively. 


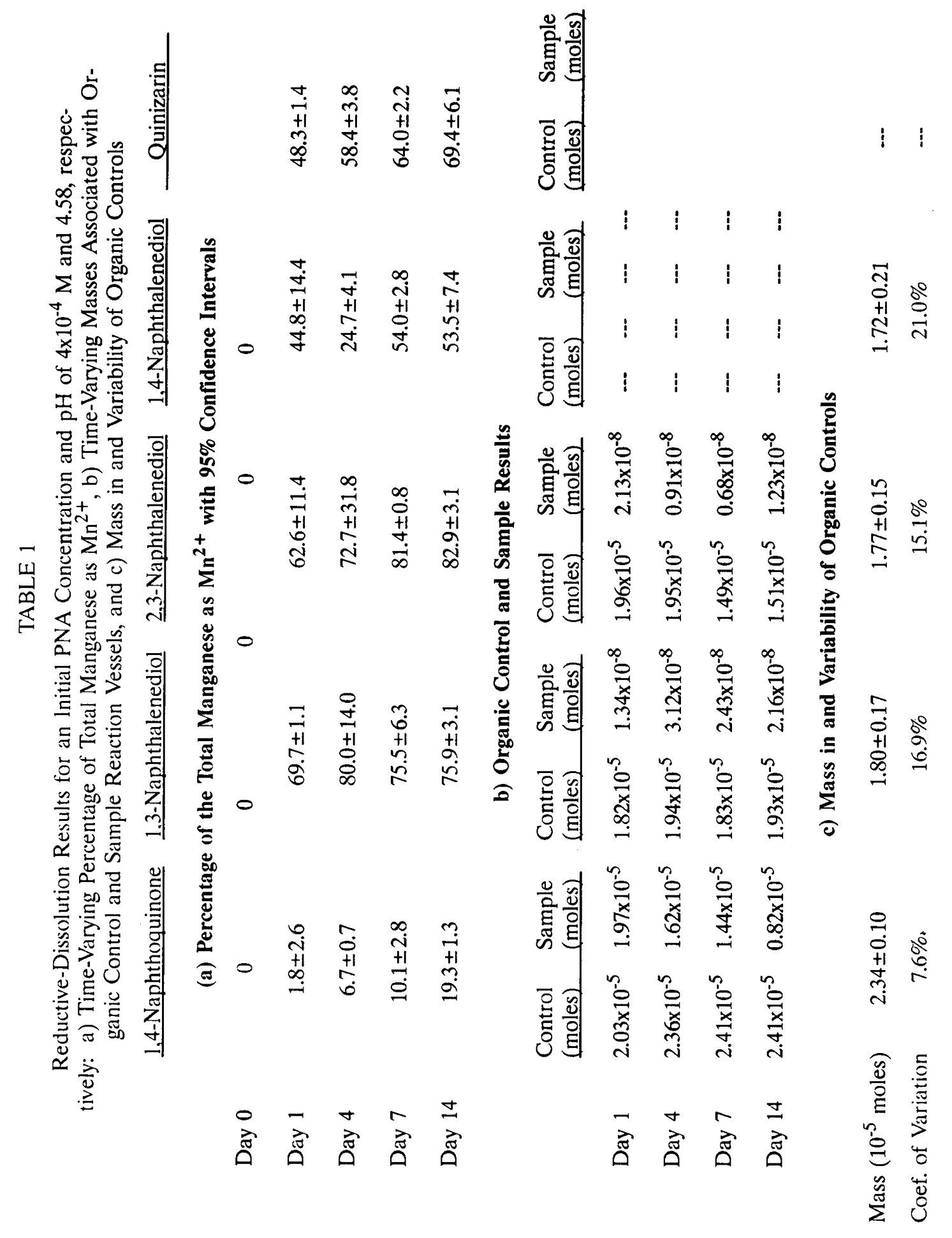


Because of the complexity related to monitoring the organic associated with its different phases (i.e., sorbed to Mn particles, parent organic, oxidation and transformation products, precipitated residue, etc.), the results associated with only the parent organic are followed in this study. As such, mass balance of the organics among all phases was not performed. The results in Figure 3 assume that separate organic controls are indicative of the initial concentration in the reaction vessel. Because separate reaction vessels are employed for organic analyses (i.e., separate samples, controls, and blanks without subsampling), this assumption may be incorrect and is violated when variability in preparing and analyzing the controls are too great. This variability is illustrated in Table 1c, which presents the mass in and variability of the organic controls.

The results associated with Quinizarin and 1,4-naphthalenediol were not presented in Figure 3 because 1) Quinizarin is insoluble in water and 2) the variability in the control concentrations of 1,4-naphthalenediol was too great. For example, the coefficient of variation $\left(\mathrm{C}_{\mathrm{v}}\right)$ of was $21 \%$ for 1,4 -naphthalenediol (Table $1 b$ ). The $C_{v}$ measures the reproducibility of a method, independent of the known concentration of the sample constituent.

The ratio between the moles of organic oxidized to the moles of $\mathrm{Mn}$ reduced from $\mathrm{Mn}\left(\mathrm{III} / \mathrm{IV}\right.$ ) to $\mathrm{Mn}^{2+}$ (i.e., "R") with 95\% confidence intervals is presented in Figure 4.

Figure 4 also includes additional results from Whelan and Sims [22]. Figure 4 illustrates little variation in the mean $\mathrm{R}$-values over time, ranging from 1.52 to 1.64 , and there are no significant differences between R-values at different time periods presented in Figure 4, based on confidence intervals. Because organic products may sorb onto the oxide surface, the reported $\mathrm{R}$ values may be lower. Lehmann and Cheng [16] noted in their $\left[{ }^{14} \mathrm{C}\right]$ ferulic-acid and Mn-oxide experiments that an increase in activity on their $\mathrm{Mn}$ oxide particles was most likely the result of reaction products readsorbing onto the oxide surface. On the other hand, McBride [8] reported that in the case of the catechol-Mn oxide reaction, an immediate darkening of the oxide suggested the adsorption of a colored oxidation product.

The dissolved $\mathrm{Mn}^{2+}$ could also have adsorbed back on to the oxide surface. In their experiments, Stone and Morgan [23] checked this possibility and noted that less than $2 \% \mathrm{Mn}^{2+}$ loss due to readsorption to the manganese oxide surface. Stone [24] notes that if the R-value becomes larger that two, then $\mathrm{Mn}^{2+}$ is accumulating at the oxide surface.

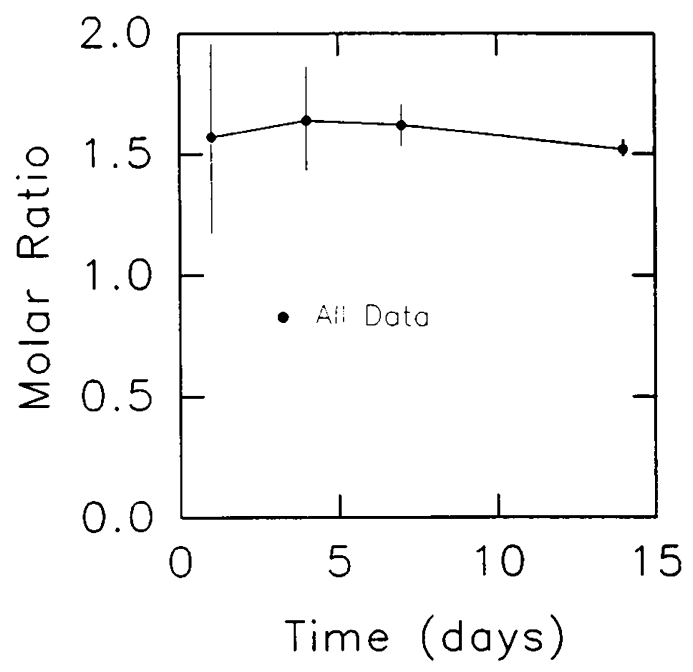

FIGURE 4. Temporal Variation in the Molar Ratio Between Organic Oxidized to Manganese Reduced with $95 \%$ Confidence Intervals. [Molar ratio analysis included experimental results for a) 1,4-, 2,3-, and 1,3-naphthalenediol; and 1,4-naphthoquinone at an initial concentration and $\mathrm{pH}$ of $4 \times 10^{-5} \mathrm{M}$ and 4.58 , respectively, b) 2,3-naphthalenediol at initial concentrations of $4 \times 10^{-5}$ and $4 \times 10^{-3} \mathrm{M}$, and c) 2,3-naphthalenediol at initial $\mathrm{pH}$ values of 5.85 and 7.85.] 


\section{DISCUSSION}

Stone and Morgan [23] noted that the "initial dissolution rate is proportional to the amount of oxide loading, which suggests that the rate at any time during dissolution is proportional to the amount of remaining oxide ...." They described this initial rate with the following autocatalytic expression:

$$
\mathrm{d}\left[\mathrm{Mn}^{2+}\right] / \mathrm{dt}=\mathrm{k}_{\exp }\left(\left[\mathrm{Mn}_{\mathrm{T}}\right]-\left[\mathrm{Mn}^{2+}\right]\right)
$$

where $k_{\text {exp }}$ is the experimentally determined rate constant and $M_{T}$ is the total manganese added to the system. To account for autocatalysis in the time rate of change of $\mathrm{Mn}^{2+}$ and the nonlinearity in this rate of change, Equation (1) can be modified to give the following expression:

$$
\mathrm{d}\left[\mathrm{Mn}^{2+}\right] / \mathrm{dt}=\mathrm{k}_{5}\left(\left[\mathrm{Mn}_{\mathrm{T}}\right]-\left[\mathrm{Mn}^{2+}\right]\right) /\left(\mathrm{K}_{\mathrm{m}}+\mathrm{t}\right)^{2}
$$

where $\mathrm{K}_{\mathrm{m}}$ and $\mathrm{k}_{5}$ are constants. By integrating Equation (2), when $\left[\mathrm{Mn}^{2+}\right]$ equals zero at time zero for the initial condition, a more appropriate expression for $\mathrm{Mn}^{2+}$ as a function of time, can be developed:

$$
\left[\mathrm{Mn}^{2+}\right]=\left[\mathrm{Mn}_{\mathrm{T}}\right]\left\{1-\exp \left(-\left(\mathrm{k}_{5} \mathrm{t} / \mathrm{K}_{\mathrm{m}}\right) /\left(\mathrm{K}_{\mathrm{m}}+\mathrm{t}\right)\right)\right\}
$$

By inspection, Equation (3) appears to describe the data presented in Figure 2. For example, 1) when time equals zero, $\left[\mathrm{Mn}^{2+}\right]$ equals zero; 2 ) during the initial times (when the exponent is $>0.01),\left[\mathrm{Mn}^{2+}\right] /\left[\mathrm{Mn}_{\mathrm{T}}\right]$ is nearly linear; 3$)$ as time becomes large, $\left[\mathrm{Mn}^{2+}\right] /\left[\mathrm{Mn}_{\mathrm{T}}\right]$ asymptotically approaches the constant "1 - $\left.\exp \left(\mathrm{k}_{5} / \mathrm{K}_{\mathrm{m}}\right) ; " 4\right)$ Equation (3) represents a rectangular hyperbola; and 5) the rate of change of $\mathrm{Mn}^{2+}$ is autocatalytic [see Equation (2)]. A rectangular-hyperbola-type shape but decreasing with time can be used to describe the naphthalenediol [Nap$(\mathrm{OH})_{2}$ ] data in Figure 3:

$$
\left[\mathrm{Nap}-(\mathrm{OH})_{2}\right]=\mathrm{S}_{\mathrm{m}} \mathrm{K}_{\mathrm{s}} /\left(\mathrm{K}_{\mathrm{s}}+\mathrm{t}\right)
$$

where $\mathrm{S}_{\mathrm{m}}$ and $\mathrm{K}_{\mathrm{s}}$ are constants. By combining Equations (2) and (4), and noting that $\left(\mathrm{K}_{\mathrm{s}} \mathrm{S}_{\mathrm{m}}\right)$ $>>\left\{2\left[\mathrm{Nap}-(\mathrm{OH})_{2}\right]\left(\mathrm{K}_{\mathrm{m}}-\mathrm{K}_{\mathrm{s}}\right)\right\}$ should be valid over most of the range, the following expression can be derived:

$$
\frac{\mathrm{d}\left[\mathrm{Mn}^{2+}\right]}{\mathrm{dt}}=\frac{\left\{\mathrm{k}_{5} /\left(\mathrm{K}_{\mathrm{m}}-\mathrm{K}_{\mathrm{s}}\right)^{2}\right\}\left(\left[\mathrm{Mn}_{\mathrm{T}}\right]-\left[\mathrm{Mn}^{2+}\right]\right)\left[\mathrm{Nap}-(\mathrm{OH})_{2}\right]^{2}}{\left\{\mathrm{~K}_{\mathrm{s}} \mathrm{S}_{\mathrm{m}} /\left(\mathrm{K}_{\mathrm{m}}-\mathrm{K}_{\mathrm{s}}\right)\right\}^{2}+\left[\mathrm{Nap}-(\mathrm{OH})_{2}\right]^{2}}
$$

In Figures 2 and 3, the sharp rate of $\mathrm{Mn}^{2+}$ reduction over the first day in Figure 2 corresponds with the sharp increase in organic oxidation (i.e., decrease in parent material) in Figure 3 . The significant drop off in $\mathrm{Mn}^{2+}$ reduction for the dihydrodiols after the first day corresponds to the 1) near complete oxidation of these organics and 2) autocatalytic effect of the Mn oxide in promoting organic oxidation.

\section{Mn(IV) to $\mathrm{Mn}(\mathrm{II})$ and Semiquinone Radicals in an Oxic Environment}

Equation (5) was derived solely based on the experimental data; it also describes the potential interrelationship between the time rate of change of $\mathrm{Mn}^{2+}$ and $\mathrm{Nap}-(\mathrm{OH})_{2}$. If this equation adequately represents this interrelationship, a similar equation could be developed solely based on stoichiometric and kinetic chemistry [25]. If the reaction is assumed to proceed through an organic free radical, the following reaction could describe the reductive dissolution 
of $\mathrm{Mn}(\mathrm{IV})$ and oxidation of naphthalenediol [Nap-(OH $\left.)_{2}\right]$ to form dissolved $\mathrm{Mn}(\mathrm{II})$ and a semiquinone radical $(\cdot \mathrm{O}-\mathrm{Nap}-\mathrm{OH})$.

$$
\mathrm{Mn}^{\mathrm{IV}} \mathrm{O}_{2}(\mathrm{~s})+2 \mathrm{Nap}-(\mathrm{OH})_{2}+2 \mathrm{H}^{+}=\mathrm{Mn}^{2+}+2(\cdot \mathrm{O}-\mathrm{Nap}-\mathrm{OH})+2 \mathrm{H}_{2} \mathrm{O}
$$

If the manganese solid is in a more reduced form [e.g., $\mathrm{Mn}$ (III)] in an oxic environment, a slightly different relationship exists between the manganese and naphthalenediol, assuming freeradical complex formation:

$$
\mathrm{Mn}^{\mathrm{III}} \mathrm{OOH}(\mathrm{s})+\mathrm{Nap}-(\mathrm{OH})_{2}+2 \mathrm{H}^{+}=\mathrm{Mn}^{2+}+\cdot \mathrm{O}-\mathrm{Nap}-\mathrm{OH}+2 \mathrm{H}_{2} \mathrm{O}
$$

Figure 4 presents the R-values for the manganese particles used in these experiments with an average R-value of $1.60 \pm 0.26$, indicating that approximately $60 \%$ of the particles are present as $\mathrm{Mn}(\mathrm{IV})$. Basing manganese stoichiometry on this R-value would result in an average particle stoichiometry of $\mathrm{MnO}_{1.8}$ with a $95 \%$ confidence interval of $\mathrm{MnO}_{1.93}$ to $\mathrm{MnO}_{1.54}$. Godtfredsen [20] prepared particles using the same procedure as those employed in this experiment. She determined a stoichiometric relationship of $\mathrm{MnO}_{1.93}$ using an oxidizing titer of excess oxalate and $\mathrm{KMnO}_{4}$. With sample transfer, the potential for organic photo-oxidation, and instrumentation error, basing the manganese-particle stoichiometry on an oxidizing titer is more accurate than basing it on chemical-reaction stoichiometry [e.g., Equation (6)], although the $95 \%$ confidence intervals on " $\mathrm{MnO}_{2}$ " stoichiometry do account for some of this uncertainty.

Figure 5 presents a possible relationship between naphthalenediol, semiquinone radical, naphthoquinone, semiquinone radical anion, and a semiquinone dianion. Stone and Morgan [26] have mechanistically described this reductive-dissolution/oxidation process in four steps: 1) precursor-complex formation (i.e., reductant adsorption), 2) electron transfer, 3) release of oxidized organic product, and 4) release of reduced metal ion. Whelan and Sims [25,27] combined auto-oxidation with these four steps and pictorially described one possible reductivedissolution/auto-oxidation process, as illustrated for naphthalenediol, in Figure 6. Following reductant adsorption, dual ligands on the oxide surface are displayed in Figure 6 to illustrate that the organic is a one-equivalent reductant and do not imply concurrent adsorption.

Four possible steps describing inner-sphere complex formation between Nap- $(\mathrm{OH})_{2}$ and the Mn oxide surface in an oxic environment can be described as follows, where the symbol " $>$ " refers to the oxide surface $[25,26]$ :

$$
\begin{aligned}
& >\mathrm{Mn}^{\mathrm{IV}}(\mathrm{OH})_{2}+2 \mathrm{Nap}-(\mathrm{OH})_{2}<\frac{\mathrm{k}_{1}}{\mathrm{k}_{-1}}>>\mathrm{Mn}^{\mathrm{IV}}(\mathrm{O}-\mathrm{Nap}-\mathrm{OH})_{2}+2 \mathrm{H}_{2} \mathrm{O} \\
& >\mathrm{Mn}^{\mathrm{IV}}(\mathrm{O}-\mathrm{Nap}-\mathrm{OH})_{2}<\frac{\mathrm{k}_{2}}{\mathrm{k}_{-2}}>>\mathrm{Mn}^{\mathrm{II}}(\cdot \mathrm{O}-\mathrm{Nap}-\mathrm{OH})_{2} \\
& >\mathrm{Mn}^{\mathrm{II}}(\cdot \mathrm{O}-\mathrm{Nap}-\mathrm{OH})_{2}+\mathrm{H}_{2} \mathrm{O}<\frac{\mathrm{k}_{3}}{\mathrm{k}_{-3}}>>\mathrm{Mn}^{\mathrm{II}} \mathrm{OH}_{2}+2(\cdot \mathrm{O}-\mathrm{Nap}-\mathrm{OH}) \\
& >\mathrm{Mn}^{\mathrm{IV}} \mathrm{O}_{2}-\left(\mathrm{Mn}^{\mathrm{II}} \mathrm{OH}_{2}\right)+2 \mathrm{H}^{+} \stackrel{\mathrm{k}_{4}}{\longrightarrow}>\mathrm{Mn}^{\mathrm{IV}}(\mathrm{OH})_{2}+\mathrm{Mn}^{2+}+\mathrm{H}_{2} \mathrm{O}
\end{aligned}
$$

where $k_{1}, k_{2}, k_{3}$, and $k_{4}$ are rate constants in the forward directions, and $k_{-1}, k_{-2}$, and $k_{-3}$ are rate constants in the reverse direction. By noting that $\mathrm{Mn}(\mathrm{II})$ still resides on the oxide surface, the $\mathrm{Mn}$ (II) products of Equation (10) can also be written as follows, because the right- and left-hand sides of Equation (12) are equivalent: 
Naphthalenediol
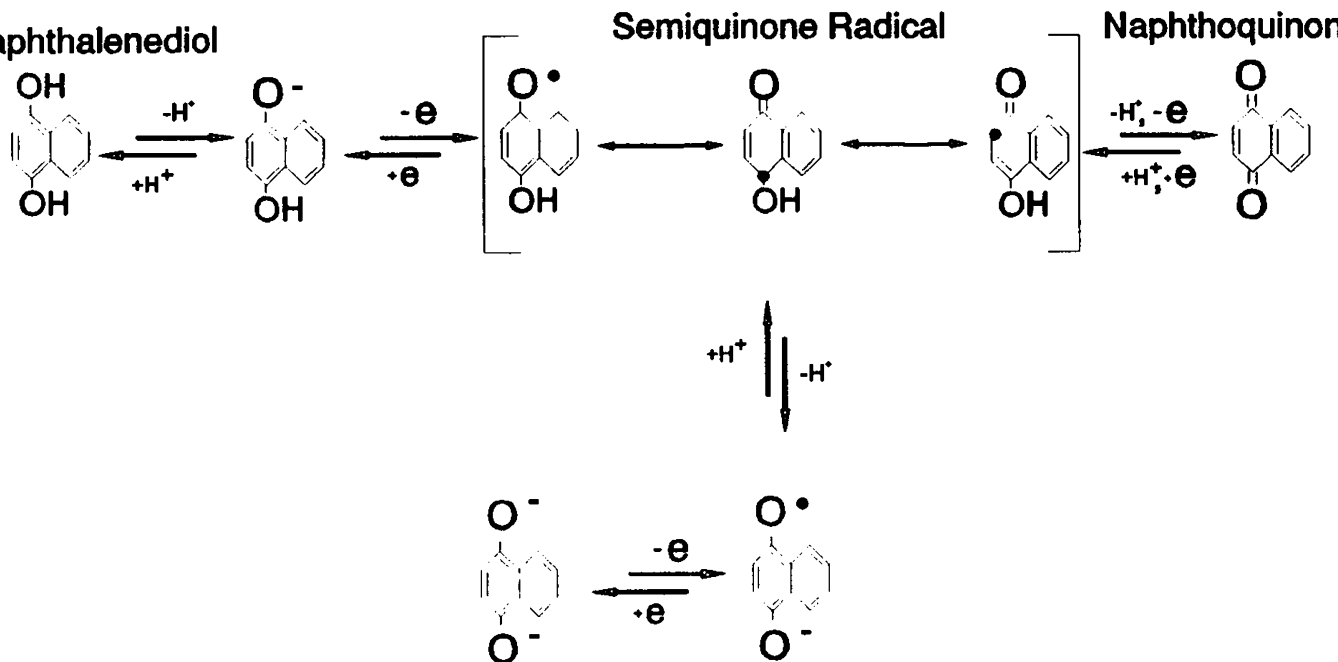

Serniquinone

Dianion

\section{Semiquinone \\ Radical \\ Anion}

FIGURE 5. Proposed Relationships Between Naphthalenediol, Semiquinone Radical, Naphthoquinone, Semiquinone Radical Anion, and Semiquinone Dianion [25,27].

$$
>\mathrm{Mn}^{\mathrm{II}} \mathrm{OH}_{2}=>\mathrm{Mn}^{\mathrm{IV}} \mathrm{O}_{2}-\left(\mathrm{Mn}^{\mathrm{II}} \mathrm{OH}_{2}\right)
$$

where " $>\mathrm{Mn}^{\mathrm{IV}} \mathrm{O}_{2}-\left(\mathrm{Mn}^{\mathrm{II}} \mathrm{OH}_{2}\right)$ " represents the reduced metal complex on the $\mathrm{Mn}(\mathrm{IV})$ surface prior to $\mathrm{Mn}(\mathrm{II})$ release.

Figure 6 and Equations (8) through (11) appear consistent with other experiments. For example, for reductant adsorption, Kummert and Stumm [9] note that Mn oxide surfaces chemisorb many phenols and other aromatic acids, suggesting inner-sphere complexation [8]. Stone and Morgan [23] suggest that electron transfer between organics and $\mathrm{Mn}$ oxides is facilitated by complexation of the organic to the oxide surface and proposed a model involving the bonding of organics to the surface via phenolic or carboxyl groups, followed by electron transfer from the organic to the oxide and the release of $\mathrm{Mn}^{2+}$ [8]. Schnitzer [2], Senesi and Schnitzer [28], and Stone and Ulrich [29] have suggested radical formation in their experiments. McBride et al. [4] note that $\mathrm{Al}^{3+}$ complexation with catechol oxidized in air at low $\mathrm{pH}$ displaces protons from phenolic groups and promotes the oxidation of catechol. The displacement of the highly electronegative proton allows the electron density to be delocalized from oxygen atoms into the aromatic ring, thereby facilitating the oxidation of catechol; thus, $o-\mathrm{C}_{6} \mathrm{H}_{4}(\mathrm{OH})_{2}$ is less susceptible to oxidation than the Al-complexed $\mathrm{C}_{6} \mathrm{H}_{4} \mathrm{O}_{2}$ - $\mathrm{Al}$, which is the chelated form of $\mathrm{C}_{6} \mathrm{H}_{4}(\mathrm{OH})_{2}$ to $\mathrm{Al}$. $\mathrm{Al}^{3+}$, by chelating with catechol, blocks the formation of quinone and, instead, promotes dimerization of radicals by coordinating to both phenolic oxygens. McBride [8] suggests similar phenolic oxidation with catechol.

\section{Rate-Limiting Mechanism of Reductive Dissolution for Manganese Oxide}

Stone and Morgan [26] note that "(m)ost reductive dissolution reactions of environmental and geochemical significance are ... controlled by surface chemical reactions" and that transportcontrolled reductive dissolution reactions represent rare cases. Schnitzer [2] suggested that the 


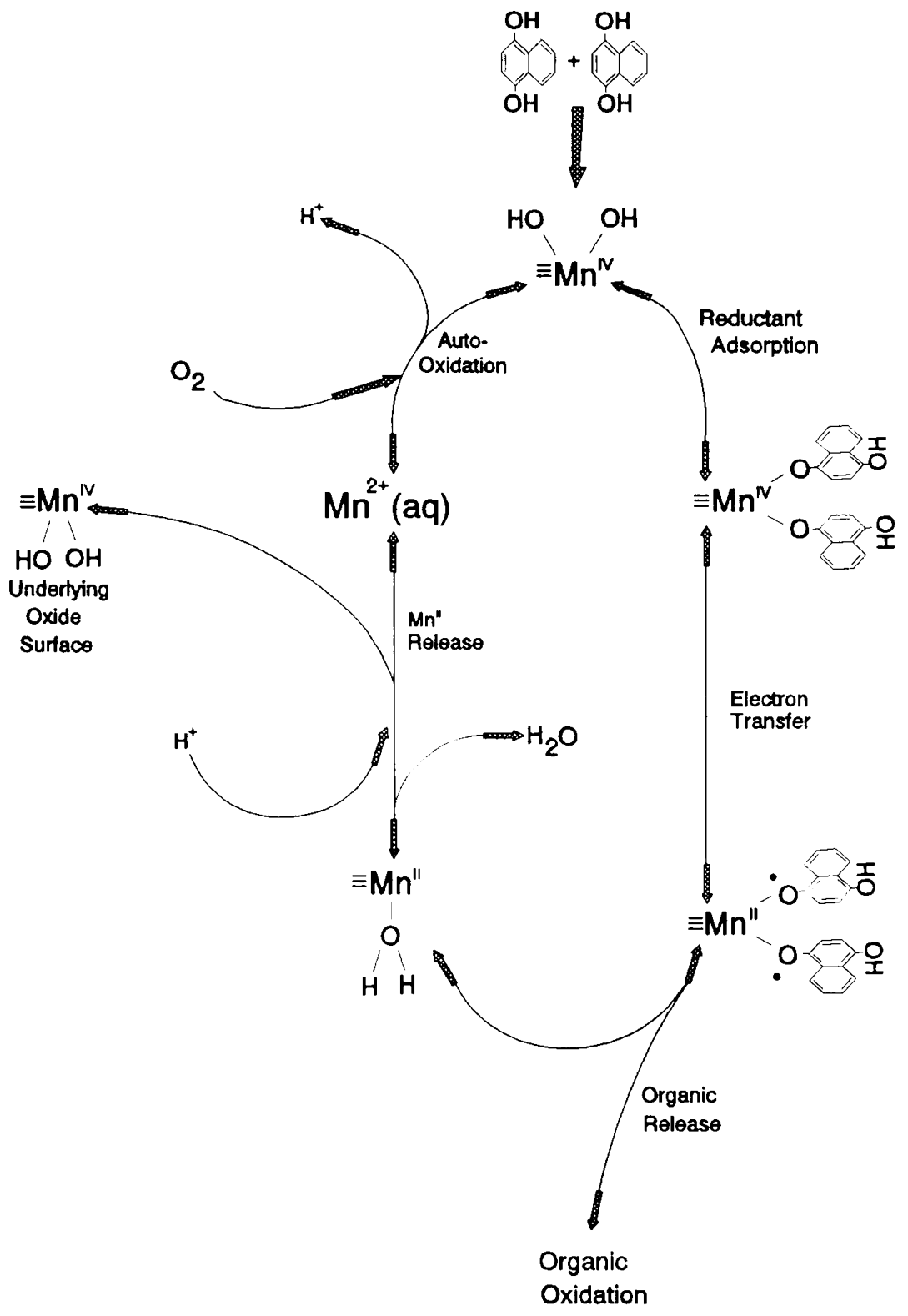

FIGURE 6. Schematic of the Reductive-Dissolution/Auto-Oxidation Process [25].

rate-determining step in oxidative polymerization of humic acids from simple phenols and phenolic acids is electron transfer. If electron transfer or organic release represents the ratelimiting step for Mn(IV) in an oxic environment, Equations (9) through (11) can be rewritten as:

$$
>\mathrm{Mn}^{\mathrm{IV}}(\mathrm{O}-\mathrm{Nap}-\mathrm{OH})_{2} \stackrel{\mathrm{k}_{6}}{-} \mathrm{Mn}^{2+}+\mathrm{H}_{2} \mathrm{O}+\text { oxidized products }
$$

where $\mathrm{k}_{6}$ is a rate constant in the forward direction. By performing a surface mass balance, assuming that the only species that contribute are $>\mathrm{Mn}^{\mathrm{IV}}(\mathrm{OH})_{2}$ and $>\mathrm{Mn}^{\mathrm{IV}}(\mathrm{O}-\mathrm{Nap}-\mathrm{OH})_{2}$, and 
assuming that other competing anions and cations are not considered, the total moles of surface sites per liter of solution $\left(\mathrm{S}_{\mathrm{T}}\right)$ can be written as follows:

$$
\mathrm{S}_{\mathrm{T}}=\left[>\mathrm{Mn}^{\mathrm{IV}}(\mathrm{OH})_{2}\right]+\left[>\mathrm{Mn}^{\mathrm{IV}}(\mathrm{O}-\mathrm{Nap}-\mathrm{OH})_{2}\right]
$$

The total $\mathrm{Mn}$ associated with the system $\left(\mathrm{Mn}_{\mathrm{T}}\right)$ can be expressed as

$$
\left[\mathrm{Mn}_{\mathrm{T}}\right]=\left[>\mathrm{Mn}^{\mathrm{IV}}(\mathrm{OH})_{2}\right]+\left[>\mathrm{Mn}^{\mathrm{IV}}(\mathrm{O}-\mathrm{Nap}-\mathrm{OH})_{2}\right]+\left[\mathrm{Mn}^{2+}\right]
$$

Under the assumption that Equations (8) and (13) can be described as an elementary reaction, rate expressions can be proposed for $>\mathrm{Mn}^{\mathrm{IV}}(\mathrm{O}-\mathrm{Nap}-\mathrm{OH})_{2}$ and $\mathrm{Mn}^{2+}[25]$ :

$$
\begin{gathered}
\mathrm{d}\left[>\mathrm{Mn}^{\mathrm{IV}}(\mathrm{O}-\mathrm{Nap}-\mathrm{OH})_{2}\right] / \mathrm{dt}=\mathrm{k}_{1}\left[\mathrm{Nap}(\mathrm{OH})_{2}\right]^{2}\left[>\mathrm{Mn}^{\mathrm{IV}}(\mathrm{OH})_{2}\right]- \\
\left(\mathrm{k}_{-1}+\mathrm{k}_{2}\right)\left[>\mathrm{Mn}^{\mathrm{IV}}(\mathrm{O}-\mathrm{Nap}-\mathrm{OH})_{2}\right] \\
\mathrm{d}\left[\mathrm{Mn}^{2+}\right] / \mathrm{dt}=\mathrm{k}_{6}\left[>\mathrm{Mn}^{\mathrm{IV}}(\mathrm{O}-\mathrm{Nap}-\mathrm{OH})_{2}\right]
\end{gathered}
$$

By combining Equations (15), (16), and (17), assuming electron transfer/organic release represents the rate-limiting step $\left\{\right.$ i.e., $\mathrm{d}\left[>\mathrm{Mn}^{\mathrm{IV}}(\mathrm{O}-\mathrm{Nap}-\mathrm{OH})_{2}\right] / \mathrm{dt}$ is at steady state\}, and using a similar approach as Stone and Morgan [26], an expression similar to that of Equation (5), which includes autocatalysis, can be developed as follows:

$$
\frac{\mathrm{d}\left[\mathrm{Mn}^{2+}\right]}{\mathrm{dt}}=\frac{\left\{\mathrm{k}_{6}\left(\left[\mathrm{Mn}_{\mathrm{T}}\right]-\left[\mathrm{Mn}^{2+}\right]\right)\right\}\left[\mathrm{Nap}-(\mathrm{OH})_{2}\right]^{2}}{\left\{\left(\mathrm{k}_{-1}+\mathrm{k}_{6}\right) / \mathrm{k}_{1}\right\}+\left[\mathrm{Nap}-(\mathrm{OH})_{2}\right]^{2}}
$$

with the total number of remaining sites at time $\mathrm{t}$ being $\left[\mathrm{Mn}_{\mathrm{T}}\right]-\left[\mathrm{Mn}^{2+}\right]$. Because 1) Equation (5) was developed strictly based on the characteristics of the data, 2) Equation (18) was theoretically developed without consideration to the experimental results, and 3) Equations (5) and (18) are virtually identical, the results suggest that the rate-limiting assumptions are appropriate. As such, " $\mathrm{k}_{5} /\left(\mathrm{K}_{\mathrm{m}}-\mathrm{K}_{\mathrm{s}}\right)^{2 "}$ in Equation (5) corresponds to $\mathrm{k}_{6}$ in Equation (18), and " $\left\{\mathrm{K}_{\mathrm{s}} \mathrm{S}_{\mathrm{m}} /\left(\mathrm{K}_{\mathrm{m}}\right.\right.$ -

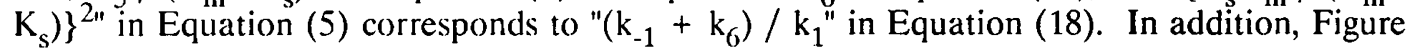
6 and Equations (10) and (13) suggest that if a free radical represented an intermediate, one potential product of abiotic-catalyzed reductive dissolution would be an oxidized or "humified" polymer. Analysis of each experiment determined the formation of a precipitate for each of the different reactants. The precipitate for 2,3-naphthalenediol is described by Whelan and Sims [22]. This observation is consistent with McBride [8] who noted that there is a greater tendency of catechol to form polymeric-oxidation products than to remain bonded to the oxide surface.

An expression similar to Equation (18) can be developed for $\mathrm{Mn}(\mathrm{III})$ :

$$
\frac{\mathrm{d}\left[\mathrm{Mn}^{2+}\right]}{\mathrm{dt}}=\frac{\left\{\mathrm{k}_{6}\left(\left[\mathrm{Mn}_{\mathrm{T}}\right]-\left[\mathrm{Mn}^{2+}\right]\right)\right\}\left[\mathrm{Nap}-(\mathrm{OH})_{2}\right]}{\left\{\left(\mathrm{k}_{.1}+\mathrm{k}_{6}\right) / \mathrm{k}_{1}\right\}+\left[\mathrm{Nap}-(\mathrm{OH})_{2}\right]}
$$

The exponent of the organic substrate is unity as one mole of $\mathrm{Mn}$ is reduced for each mole of organic oxidized. For a mixture of $\mathrm{Mn}$ (III/IV) particles under nonhomogeneous conditions, the rate of change of $\mathrm{Mn}^{2+}$ can be calculated as:

$$
\frac{\mathrm{d}\left[\mathrm{Mn}^{2+}\right]}{\mathrm{dt}}=\sum_{\mathrm{i}=1}^{\mathrm{m}} \frac{\mathrm{k}_{6 \mathrm{i}}\left(\left[\mathrm{Mn}_{\mathrm{T}}\right]_{\mathrm{i}}-\left[\mathrm{Mn}^{2+}\right]_{\mathrm{i}}\right)\left[\mathrm{Nap}-(\mathrm{OH})_{2}\right]^{\mathrm{Ri}}}{\left\{\left(\mathrm{k}_{-1 \mathrm{i}}+\mathrm{k}_{6 \mathrm{i}}\right) / \mathrm{k}_{1 \mathrm{i}}\right\}+\left[\mathrm{Nap}-(\mathrm{OH})_{2}\right]^{\mathrm{Ri}}}
$$




$$
\begin{aligned}
{\left[\mathrm{Mn}_{\mathrm{T}}\right] } & =\sum_{\mathrm{i}=1}^{\mathrm{m}}\left[\mathrm{Mn}_{\mathrm{T}}\right]_{\mathrm{i}} \\
{\left[\mathrm{Mn}^{2+}\right] } & =\sum_{\mathrm{i}=1}^{\mathrm{m}}\left[\mathrm{Mn}^{2+}\right]_{\mathrm{i}}
\end{aligned}
$$

where $\mathrm{m}$ is the number of different forms of $\mathrm{Mn}$ molecules (e.g., $\mathrm{MnO}_{2}, \mathrm{MnOOH}, \mathrm{Mn}_{2} \mathrm{O}_{3}, \delta$ $\mathrm{MnO}_{2}$, etc.) undergoing reductive dissolution, $\mathrm{i}$ is the index on the number of different forms of $\mathrm{Mn}$ molecules undergoing reductive dissolution, $\mathrm{R}$ is ratio between the moles of organic oxidized to the moles of $\mathrm{Mn}$ reduced to $\mathrm{Mn}^{2+}$, and all other terms retain their previous definition.

\section{Substrate Reactivity as a Function of Diol/Dione Structure}

The literature contains more examples illustrating diol reactivity than those of diones, but if appropriately linked through a common intermediate, their reactivities might be similar. For example, Figure 5 presents a conceptual model linking 1,4-naphthalenediol with 1,4-naphthoquinone through a semiquinone radical. If the semiquinone radical is readily formed from both directions, then similar amounts of reduced $\mathrm{Mn}^{2+}$ should occur.

A preliminary experiment was performed that investigated the reactivity of a complement set of diol and dione chemicals. 1,4-naphthalenediol and 1,4-naphthoquinone were separately combined with $\mathrm{Mn}$ oxide particles under exactly the same experimental conditions. The results of the reductive dissolution are presented in Figure 2. After one day, the fraction of total $\mathrm{Mn}^{2+}$ in solution was nearly 25 times higher for the 1,4-naphthalenediol than for the 1,4-naphthoquinone, and after 14 days, it was nearly three times higher. This trend was exhibited by every other constituent in this study containing diol functional groups, as illustrated by Figure 2 .

Quinizarin, which is sparingly soluble in water, demonstrated a four- to 27-fold increase in reductive dissolution of the $\mathrm{Mn}$ oxides over that of the 1,4-naphthoquinone and up to a 1.3fold increase over that of 1,4-naphthalenediol. These results indicate that even sparingly soluble PNA compounds with the appropriate functional groups are susceptible to oxidation and suggest that even larger PNA compounds might be susceptible to abiotic-catalyzed oxidation. The results tend to suggest that the rate of dissolution to Quinizarin's solubility limit is not rate limiting.

\section{SUMMARY}

Research has indicated that organic compounds containing diol and dione functional groups tend to be susceptible to reactivity, specifically oxidation. The purpose of this research was to investigate the nature of abiotic redox reactions in a simplified, oxic, aqueous system consisting of PNA compounds and $\mathrm{MnO}_{2}$ and to present a possible mathematical explanation for this abiotic process. Results demonstrated significant oxidation of two-and three-ringed PNA compounds, especially those containing dihydrodiol functional groups, suggesting that higher molecular-weight, multiple-ringed diol/dione aromatics could be oxidized using Mn oxide reductive dissolution. Even the three-ringed aromatic Quinizarin, which is relatively insoluble in water, reduced $70 \%$ of the $\mathrm{MnO}_{2}$ over a 14-day period, suggesting that the rate-limiting step is not organic-compound dissolution.

The experimental results indicated 1) a rectangular-hyperbola-type shape for both reactants, 2) autocatalysis of the $\mathrm{Mn}, 3$ ) the formation of a precipitate as a product, and 4) that between one and two moles of organic were oxidized for each mole of $\mathrm{Mn}$ reduced. The results also suggested that 1) dihydrodiols were more reactive than their complementing dione form and 2) resonance stabilization did not affect the degree of oxidation associated with various forms of naphthalenediol, which might suggest that reactivity is based more on the ability to form a semiquinone radical (all of the tested diols) than on the ability to have a corresponding dione structure. 
Mathematical algorithms were developed from two different perspectives with the development being independent of the PNA utilized in the experiment. First, equations were developed that were solely based on the experimental data, which described the temporal variation of $\mathrm{Mn}^{2+}$ and PNA. A second independent set of algorithms were developed based on the stoichiometric and kinetic equations theoretically describing the reductive-dissolution process. In addition to matching experimental results, these theoretically based algorithms suggested 1) the possible formation of a free-radical intermediate, 2) the nonrate-limiting and unidirectional release of $\mathrm{Mn}^{2+}$ from the oxide surface, and 3) electron transfer/organic release as the ratelimiting step. A comparison of these two sets of independent equations $\{$ i.e., based on experimental data [Equation (5)] and theoretically derived expressions [Equation (18)]\} indicated the development of the same equation. A comparison of the experimental results with the mathematical results suggests that the assumptions of the theoretically derived equations may provide insight into the reductive-dissolution process and the oxidation and potential "humification" of PNA compounds.

\section{ACKNOWLEDGMENTS}

Funding for this research was supplied by the U.S. Geological Survey and U.S. Environmental Protection Agency's Robert S. Kerr Environmental Research Laboratory (through Dynamac Corporation) through grants to Utah State University (USU) under Award Nos. 14-080001-G1723 and 68-C8-0058, respectively. Thanks are extended to Drs. J. J. Jurinak and D. K. Stevens of USU, J.-M. Bollag of The Pennsylvania State University, A. T. Stone and K. L. Godtfredsen of The Johns Hopkins University, and P. M. Huang of the University of Saskatchewan for providing technical information during the various phases of this work. Appreciation is extend to Mr. W. R. Gorst of Battelle, Pacific Northwest Laboratories and Ms. L. Hemphill of the Utah Water Research Laboratory for performing the editorial review of this manuscript.

\section{REFERENCES}

1. Bollag, J.-M. and Myers, C. Sci. Tot. Environ, 117, 357 (1992).

2. Schnitzer, M. Whither Soil Research, Publications of the 12th Int. Congr. Soil Sci., New Delhi, India, 5, 67 (1982).

3. Wang, M. C. and Huang, P. M. Sci. Tot. Environ, 113, 147 (1992).

4. McBride, M. B., Sikora, F. J., and Wesselink, L. G. Soil Sci. Soc. Am. J, 52, 985 (1988).

5. Qiu, X. and McFarland, M. J. Haz. Waste Haz. Mat, 8, 115 (1991).

6. Shindo, H. and Huang, P. M. Soil Sci. Soc. Amer. J, 48, 927 (1984).

7. Shindo, H. and Huang, P. M. Nature (London), 298, 363 (1982).

8. McBride, M. B. Soil Sci. Soc. Am. J, 51, 1466 (1987).

9. Kummert, R. and Stumm, W. J. Colloid Interface Sci, 75, 373 (1980).

10. Shindo, H. and Huang, P. M. Soil Sci, 139, 505 (1985).

11. Kononova, M. M. Soil Components, Vol. I: Organic Components, Gieseking, J. C. Ed., Springer-Verlag, New York, 1975, 74. 
12. Schnitzer, M. and Khan, S. U. Humic Substances in the Environment, Marcel Dekker, New York, 1972.

13. Wang, T. S. C., Kao, M.-M. and Huang, P. M. Soil Sci, 129, 333 (1980).

14. Wang, T. S. C., Huang, P. M., Chou, C.-H. and Chen, J.-H. Interaction of Soil Minerals With Natural Organics and Microbes. Special Publication No. 17, Soil Science Society of America, Madison, WI, 1986, 251.

15. Laha, S. and Luthy, R. G. Environ. Sci. Technol, 24, 363 (1990).

16. Lehmann, R. G. and Cheng, H. H. Soil Sci. Soc. Am. J, 52, 1304 (1988).

17. Lehmann, R. G., Cheng, H. H. and Harsh, J. B. Soil Sci. Soc. Am. J, 51, 352 (1987).

18. Mihelcic, J. R. and Luthy, R. G. Appl. Environ. Microbiol, 54, 1182 (1988).

19. Murray, J. W. J. Colloid. Inter. Sci, 46, 357 (1974).

20. Godtfredsen, K. L. Release of $\mathrm{MnO}_{2}$-Bound $\mathrm{Co}, \mathrm{Ni}$, and $\mathrm{Cu}$ by Acidification, Competitive Sorption, Complexation, and Reductive Dissolution, Ph.D. Dissertation, The Johns Hopkins University, Baltimore, MD, 1992,

21. Whelan, G. Surface-Induced Oxidation of Multiple-Ringed Diol and Dione Aromatics by Manganese Dioxide, Ph.D. Dissertation, Utah State University, Logan, UT, 1992.

22. Whelan, G. and Sims, R. C. Mn-Catalyzed Oxidation of Naphthalenediol, Haz. Waste Haz. Mat, (1995) (accepted).

23. Stone, A. T. and Morgan, J. J. Environ. Sci. Technol, 18, 450 (1984).

24. Stone, A. T. The Reduction and Dissolution of Manganese(III) and (IV) Oxides by Organics, Ph.D. Dissertation, California Institute of Technology, Pasadena, CA, 1983.

25. Whelan, G. and Sims, R. C. Haz. Waste Haz. Mat, 9, 245 (1992).

26. Stone, A. T. and Morgan, J. J. Aquatic Surface Chemistry, Stumm, W., Ed., Wiley, New York, 1987, 221.

27. Whelan, G. and Sims, R. C. Proceedings of SUPERFUND '90, Hazardous Materials Control Research Institute, Silver Spring, MD, 1990, 820.

28. Senesi, N. and Schnitzer, M. Soil Sci, 123, 224 (1977).

29. Stone, A. T. and Ulrich, H. J. J. Colloid. Inter. Sci, 132, 509 (1989).

Address reprint requests to:

Dr. Gene Whelan

Battelle, Pacific Northwest Laboratories

P.O. Box 999

Richland, Washington 99352 